\title{
Healthy worker effect in the total Finnish population
}

\author{
K VINNI AND M HAKAMA \\ From the Department of Public Health, University of Tampere, Tampere, Finland
}

ABSTRACT The selection due to the "healthy worker effect" was estimated from a random sample of the total Finnish population. The sample of 20000 people was followed for changes in occupations from 1960 to 1970 and for deaths in 1971-5. Those entering the active work force had a standard mortality ratio of 70 , indicating a healthy population selection effect. Those staying in the same occupational category from 1960 to 1970 had a $20 \%$ lower mortality than those who did not. This survivor population effect was due to changes to another occupational group and to early retirement. These factors had an inverse effect on the survival history of an occupational group.

Epidemiological studies of occupational exposures indicate that the mortality of a working population is often less than that of the total population. The difference is due to a bias called the "healthy worker effect", 1 which results from a combination of various selective forces at different stages of the individual's occupational history. ${ }^{2}$

The purpose of this study is to give quantitative estimates of these selective factors. This assumes a follow-up of both occupations and deaths in a population. Empirical data are taken from Finnish vital statistics.

\section{Material and methods}

In Finland statistical data on vital events are based on the National Population Registry. In addition a population census is carried out every 10 years to provide further information on environmental and other aspects of the population. Each person's occupation and date of death are recorded in the Population Registry.

The basic series consisted of a random sample from the total Finnish population on 31 December 1960 drawn from the 1960 census lists by the Central Statistical Office of Finland. This sample was followed up to the 1970 census. The occupations in 1960 and 1970 were recorded for the population included in the sample. The linkage of 1960 and 1970 data occurred by means of name and date of birth. In the original sample of 1960 there were about 4000 cases not found in 1970 . The majority of these failures were from deaths and migration. It was estimated that the number of losses for follow-up was 1100,3 mainly due to young women changing their family name when they married.

Those living on 31 December 1970 were followed up from 1971 to 1975 . During this second stage, deaths were recorded by linking the population sample with the register of all death certificates issued in Finland in 1971-5.

People belonging to the sample were classified by age, sex, and occupation in 1960 and in 1970. Occupational categories were based on the Scandinavian nomenclature where 11 main occupational classes were distinguished ${ }^{4}$; the classes were combined into six categories in this study.

1 Administration-Those in administration, management, science, and the arts-for instance, physician, nurse, teacher, manager, clerk, typist.

2 Sales-Shopkeeper, dealer, vendor, salesman.

3 Agriculture-Occupations in agriculture, forestry, and fishing-for example, farmer, forestry technician, fisherman, lumberjack.

4 Transport-Transport and communications work -for instance, driver, sailor, pilot, telegrapher, postman.

5 Industry-Including manufacturing and mining workers and labourers.

6 Services-Including police, armed forces, waiter, porter, janitor, domestic.

Age was classified into four groups (20-44, $45-54,55-59,60-64)$. The final number of strata was $11 \times 11 \times 4 \times 2=968$. The observed number of deaths in 1971-5 was estimated within each of the 968 strata. The expected number of deaths was found for the 968 strata by multiplying the personyears for each stratum by the age-sex-specific mortality rates for the total sample. 
Table 1 Random sample from the total Finnish population on 31 December 1960, by occupational status in 1960 and 1970

\begin{tabular}{|c|c|c|c|c|c|c|c|c|c|c|}
\hline \multirow[t]{2}{*}{ Occupational category in 1960} & \multicolumn{10}{|c|}{ Occupational category in 1970} \\
\hline & 1 & 2 & 3 & 4 & 5 & 6 & $\begin{array}{l}\text { Active } \\
\text { work force }\end{array}$ & $\begin{array}{l}\text { Not } \\
\text { working }\end{array}$ & $\begin{array}{l}\text { Not found } \\
\text { in } 1970\end{array}$ & $\begin{array}{l}\text { Total } \\
\text { sample }\end{array}$ \\
\hline $\begin{array}{l}1 \text { Administration } \\
2 \text { Sales } \\
3 \text { Agriculture } \\
4 \text { Transport } \\
5 \text { Industry } \\
6 \text { Services } \\
\text { Active work force } \\
\text { Not working }\end{array}$ & $\begin{array}{r}747 \\
45 \\
34 \\
17 \\
98 \\
33 \\
974 \\
649\end{array}$ & $\begin{array}{r}43 \\
236 \\
19 \\
12 \\
57 \\
14 \\
381 \\
290\end{array}$ & $\begin{array}{r}13 \\
7 \\
1188 \\
21 \\
58 \\
16 \\
1303 \\
419\end{array}$ & $\begin{array}{r}10 \\
9 \\
67 \\
292 \\
79 \\
12 \\
469 \\
191\end{array}$ & $\begin{array}{r}38 \\
41 \\
299 \\
95 \\
1305 \\
36 \\
1814 \\
1035\end{array}$ & $\begin{array}{r}18 \\
13 \\
43 \\
13 \\
87 \\
260 \\
434 \\
463\end{array}$ & $\begin{array}{r}869 \\
351 \\
1650 \\
450 \\
1684 \\
371 \\
5375 \\
3047\end{array}$ & $\begin{array}{r}198 \\
99 \\
885 \\
76 \\
424 \\
178 \\
1860 \\
5395\end{array}$ & $\begin{array}{r}272 \\
190 \\
612 \\
97 \\
445 \\
262 \\
1878 \\
2307\end{array}$ & $\begin{array}{r}1339 \\
640 \\
3147 \\
601 \\
2575 \\
811 \\
9113 \\
10749\end{array}$ \\
\hline Total & 1623 & 671 & 1722 & 660 & 2849 & 897 & 8422 & 7255 & 4185 & 19862 \\
\hline
\end{tabular}

The strata were recombined to provide estimates of the healthy worker effect. The mortality for those entering an occupational category was estimated by comparing the observed and expected numbers of deaths of those not in the working population in 1960 but belonging to a specific occupational category in 1970. This population is called the subgroup entering the working population.

Similarly, observed and expected numbers of deaths were estimated for those who, from 1960 to 1970, stayed within the same occupational category, changed from one occupational category to another, and retired because of ill health or age.

Thus we had five stages in the occupational history (entering, staying, changing, retiring because of ill health, and retiring because of old age). Within each stage the series was combined by occupation into six broad occupational categories, yielding a group.

The standardised mortality ratios (SMR) were estimated as the ratio of observed to expected number of deaths and multiplied by 100 . P-values for SMRs were estimated by assuming the observed number of deaths to be distributed according to the Poisson probability law.

\section{Results}

The original sample of 19862 subjects (table 1), decreased by 4185 from 1960 to 1970 . These 15677 were followed up from 1971 to 1975 for mortality.

During this second follow-up stage the total number of deaths was 875 (table 2), 191 of which occurred among the population working in both 1960 and $1970 ; 684$ deaths occurred in the population working neither at the beginning (1960) nor at the end (1970) of the first follow-up stage.

From 1960 to 19703047 entered the working population. These were mainly young people entering the work force for the first time. There were 24 deaths in this population during 1971-5. The total mortality of this population was $30 \%$ less than that of the total population (table 3 ).

Of the 5375 who stayed within the same occupational group, 151 died. The mortality was $20 \%$ less than that for the total population (table 4). Those who changed their occupational group had a low mortality rate (SMR $=70$, table 5). Those retiring aged under 65 had a $30 \%$ higher mortality rate than the total population (table 6). The mortality of those

Table 2 Number of deaths in the sample during 1971-5, by occupational category in 1960 and 1970

\begin{tabular}{|c|c|c|c|c|c|c|c|c|c|}
\hline \multirow[t]{2}{*}{ Occupational category in 1960} & \multicolumn{9}{|c|}{ Occupational category in 1970} \\
\hline & 1 & 2 & 3 & 4 & 5 & 6 & $\begin{array}{l}\text { Active work } \\
\text { force }\end{array}$ & Not working & Total \\
\hline $\begin{array}{l}1 \text { Administration } \\
2 \text { Sales } \\
3 \text { Agriculture } \\
4 \text { Transport } \\
5 \text { Industry } \\
6 \text { Services } \\
\text { Active work force } \\
\text { Not working }\end{array}$ & $\begin{array}{r}20 \\
1 \\
1 \\
0 \\
4 \\
1 \\
27 \\
7\end{array}$ & $\begin{array}{r}1 \\
10 \\
0 \\
0 \\
0 \\
1 \\
12 \\
2\end{array}$ & $\begin{array}{r}0 \\
0 \\
62 \\
0 \\
5 \\
0 \\
67 \\
5\end{array}$ & $\begin{array}{r}0 \\
2 \\
0 \\
13 \\
1 \\
0 \\
16 \\
1\end{array}$ & $\begin{array}{r}2 \\
1 \\
8 \\
1 \\
39 \\
3 \\
54 \\
4\end{array}$ & $\begin{array}{r}1 \\
0 \\
0 \\
1 \\
6 \\
7 \\
15 \\
5\end{array}$ & $\begin{array}{r}24 \\
14 \\
71 \\
15 \\
55 \\
12 \\
191 \\
24\end{array}$ & $\begin{array}{r}29 \\
13 \\
152 \\
15 \\
96 \\
24 \\
329 \\
331\end{array}$ & $\begin{array}{r}53 \\
27 \\
223 \\
30 \\
151 \\
36 \\
520 \\
355\end{array}$ \\
\hline Total & 34 & 14 & 72 & 17 & 58 & 20 & 215 & 660 & 875 \\
\hline
\end{tabular}


Table 3 Mortality of those entering the work force between 1960 and 1970, by occupational category in 1970

\begin{tabular}{lccc}
\hline Occupational category in 1970 & Observed & Expected & SMR \\
\hline Administration & 7 & $7 \cdot 0$ & 100 \\
Sales & 2 & $2 \cdot 8$ & 70 \\
Agriculture & 5 & $6 \cdot 2$ & 80 \\
Transport & 1 & $1 \cdot 8$ & 60 \\
Industry & 4 & $9 \cdot 9$ & 40 \\
Services & 5 & $5 \cdot 3$ & 90 \\
Total & 24 & $33 \cdot 0$ & 70 \\
\hline
\end{tabular}

SMR $=$ Standardised mortality ratio.

Table 4 Mortality for those staying in the same occupational group between 1960 and 1970, by occupational category

\begin{tabular}{|c|c|c|c|}
\hline Occupational category $1960-70$ & Observed & Expected & $S M R$ \\
\hline $\begin{array}{l}\text { Administration } \\
\text { Sales } \\
\text { Agriculture } \\
\text { Transport } \\
\text { Industry } \\
\text { Services }\end{array}$ & $\begin{array}{r}20 \\
10 \\
62 \\
13 \\
39 \\
7\end{array}$ & $\begin{array}{l}25 \cdot 6 \\
10 \cdot 0 \\
70 \cdot 6 \\
10 \cdot 6 \\
51 \cdot 1 \\
11 \cdot 3\end{array}$ & $\begin{array}{r}80 \\
100 \\
90 \\
120 \\
80 \\
60\end{array}$ \\
\hline Total & $151^{*}$ & $179 \cdot 2$ & 80 \\
\hline
\end{tabular}

$* \mathrm{p}<0.05$.

SMR = Standardised mortality ratio.

Table 5 Mortality for those changing occupational category between 1960 and 1970, by occupational category in 1960

\begin{tabular}{lccc}
\hline Occupational category in 1960 & Observed & Expected & SMR \\
\hline Administration & 4 & $8 \cdot 2$ & 50 \\
Sales & 4 & $3 \cdot 7$ & 110 \\
Agriculture & 9 & $12 \cdot 7$ & 70 \\
Transport & 2 & $5 \cdot 7$ & 40 \\
Industry & 16 & $21 \cdot 4$ & 70 \\
Services & 5 & $3 \cdot 9$ & 130 \\
Total & $40^{*}$ & $55 \cdot 6$ & 70 \\
\hline
\end{tabular}

$* \mathrm{p}<0.05$.

SMR $=$ Standardised mortality ratio.

Table 6 Mortality of those retiring before the age of 65 between 1960 and 1970, by occupational category in 1960

\begin{tabular}{lccc}
\hline Occupational category in 1960 & Observed & Expected & SMR \\
\hline Administration & 3 & $5 \cdot 3$ & 60 \\
Sales & 4 & $2 \cdot 2$ & 180 \\
Agriculture & 55 & $44 \cdot 9$ & 120 \\
Transport & 3 & $3 \cdot 0$ & 100 \\
Industry & 23 & $14 \cdot 7$ & 160 \\
Services & 8 & $4 \cdot 7$ & 170 \\
Total & $96^{*}$ & $74 \cdot 8$ & 130 \\
\hline
\end{tabular}

$* \mathrm{p}<0.05$.

SMR $=$ Standardised mortality ratio.
Table 7 Mortality of those retiring because of age (over 65) between 1960 and 1970, by occupational category in 1960

\begin{tabular}{lccc}
\hline Occupational category in 1960 & Observed & Expected & SMR \\
\hline Administration & 26 & $27 \cdot 2$ & 100 \\
Sales & 9 & $13 \cdot 3$ & 70 \\
Agriculture & 97 & $93 \cdot 1$ & 100 \\
Transport & 12 & $13 \cdot 9$ & 90 \\
Industry & 73 & $73 \cdot 3$ & 100 \\
Services & 16 & $24 \cdot 4$ & 70 \\
Total & 233 & $245 \cdot 2$ & 100 \\
\hline
\end{tabular}

SMR = Standardised mortality ratio.

retiring because of age was the same as that of the total population (table 7). During every stage of the occupational history there were differences by occupational group.

\section{Discussion}

More than 100 years ago Ogle described the healthy worker effect, ${ }^{5}$ relating it to the different requirements of various occupations and individual differences in physical capacity. The selection in entering the work force is commonly called the "healthy population selection effect" and the ability to stay within the same occupation the "survivor population effect."' 2 Furthermore, the healthy worker effect was shown to affect the different population groups with a different intensity and direction..$^{6-9}$ In our study we measured the healthy population selection effect by comparing the mortality of those entering the working population with that of the general population. The survivor population effect was measured by the mortality of those staying at least 10 years in the same occupational group and comparing it with the mortality of those not staying in the same category.

In addition to the basic mental and physical requirements the selection depends on the environment reflected through the unemployment rate, work supply, health examinations, and fitness tests. All these factors are independent of the occupational exposures, which are usually the objective of an occupational study. Occupational exposures are confounded with the effect on the survival in industry, however.

Even if the healthy worker effect and its components have been known for more than 100 years, there are few quantitative estimates for the effect. Fox and Collier ${ }^{5}$ followed up the total industrial population exposed to polyvinyl chloride for more than 15 years. They found that the total mortality within five years was only $37 \%$ of that expected. This result is in agreement with several other studies ${ }^{10-12}$ 
that have not taken into account the healthy population selection effect. This bias can be partly assessed by comparing the mortality risks with the length of the follow-up. ${ }^{13-15}$ In the study on the mortality of workers exposed to polyvinyl chloride the healthy worker effect had almost disappeared 15 years after entry. 5

In this study we followed up a random sample of the total Finnish population for changes in occupations for 10 years, after which we followed the same population for deaths for five years. This scheme allowed us to evaluate the healthy worker effect and its components in the total Finnish population and in any occupational category.

The healthy population selection effect was estimated by comparing the mortality of those entering the work force in the 1960 s with that of the total population. The survival in industry was evaluated by comparing the mortality of those entering, staying in, and retiring from work with that of the total Finnish population. The healthy population selection effect was found to be about $30 \%$. The mortality of those entering the work force was $50 \%$ $(70 / 130)$ of the mortality of those who retired before the age of 65 .

The survival in industry was also shown. The mortality of those staying within the same occupational category was $60 \%(80 / 130)$ of the mortality of those who retired before the age of 65 . On the other hand, the mortality of those who changed from one occupational group to another was only $90 \%$ $(70 / 80)$ of that of those who stayed within the same group from 1960 to 1970 . Thus there were two components in the survivor population effect. Those who retired have a high mortality, whereas those who changed occupation are likely to be healthier than the total population. The survivor population effect is reduced when the components with these inverse selective effects are combined. The mortality of those staying in the working population was $80 \%(80 / 100)$ of the mortality of those who did not stay in the same occupational group.

There were differences in the survivor population effect by occupational category. The ratio of SMR for those who stayed in transport to the SMR for those who changed from transport to another group or retired before the age of 65 was $2 \cdot 2$ whereas the corresponding ratio for the services was only $0 \cdot 4$. Fox and Collier ${ }^{5}$ found the mortality of men even after 15 years in industry to be $50 \%$ lower than the mortality of those who did not stay in industry. This estimate is equal to that derived from the present series $(80 / 110)$.

The total healthy worker effect can be characterised by the ratio of SMR of those entering the working population to the SMR of those either changing occupational category or retiring before the age of 65 . For the total series this ratio was $0 \cdot 7$. The highest ratio was found for administration (1.9) and the lowest for industry $(0 \cdot 4)$.

The healthy worker effect also depends on the general population distribution by occupation and changes in the distribution. In Finland the occupational structure has changed significantly, especially in the 1960 s. The population in agriculture decreased by about $40 \%$ from 35 to $20 \%$ of the active work force and the population in services and in industry increased. ${ }^{16}$ This may account for some of the differences in mortality between these occupations.

We have also assumed that those working in 1960 but not in 1970 have retired. Some have gone into the non-active work force-for instance, housewives. Their number is likely to be small, however, because of economic expansion and other factors.

For the present purposes a population of 20000 is small enough to allow a substantial random variation in the results. To reduce random error only the total mortality was considered, and broad occupational categories were used. The crude occupational definition and a lack of attention to cause of death are not likely to show specific occupational exposures, and the results may indicate differences in social status rather than in occupational and working environment. Furthermore, the scheme used did not allow variation in the length of the follow-up, which is also a determinant of the healthy worker effect. ${ }^{2}$

Within the limits of these crude classifications, however, we were able to find substantial and statistically significant selection into work and selection during the occupational history. Probably for specific occupational and disease groups the healthy worker effect exceeds that indicated by the present figures. It was also shown that the healthy worker effect can be split into several components and that the effect causes either a positive or a negative bias in the occupational studies, depending on the occupational category. The latter fact is only seldom emphasised, partly because the subject of most studies has been an industrial population with a strong and consistent pattern of healthy worker effect. The scheme used in our paper is directly applicable to specific studies affected by the healthy worker effect.

We thank the Central Statistical Office of Finland for permission to use their material.

\section{References}

${ }^{1}$ Goldschmidt JR. What do we expect from an occupational cohort? J Occup Med 1975;17:126. 
${ }^{2}$ Fox AJ, Collier PF. Low mortality rates in industrial cohort studies due to selection for work and survival in the industry. Br J Prev Soc Med 1976;30:225-30.

${ }^{3}$ Sauli H. Mortality: occupational mortality in 1971-75. Studies No 54. Helsinki: Central Statistical Office of Finland, 1979.

4 Pohjoismainen ammattiluokittelu (suomenkielinen laitos). Helsinki: Valtioneuvoston kirjapaino, 1963.

${ }^{5}$ Fox AJ, Collier PF. Mortality experience of workers exposed to vinyl chloride monomer in the manufacture of polyvinyl chloride in Great Britain. $\mathrm{Br} J$ Ind Med 1977;34:1-10.

- McMichael AJ, Haynes SG, Tyroler HA. Observations on the evaluation of occupational mortality data. $J$ Occup Med 1975;17:128-31.

' McMichael AJ. Standardized mortality ratios and the "healthy worker effect"; Scratching beneath the surface. J Occup Med 1976;18:165-8.

${ }^{8}$ Gaffey WR. Critique of the standardized mortality ratio. J Occup Med 1976;18:157-60.
- Jeune B. Mortality of male members of the Danish Semi-skilled and Unskilled Workers' Union in 1973. Int J Epidemiol 1977;6:247-57.

${ }^{10}$ Lloyd JW, Ciocco A. Long-term mortality study of steel workers: Methodology. J Occup Med 1969;11:299-310.

${ }^{11}$ Luepker RV, Smith ML. Mortality in unionized truck drivers. J Occup Med 1978;20:677-82.

${ }_{12}$ Musk AW, Monson RR, Peters JM, Peters RK. Mortality among Boston firefighters 1915-75. Br J Ind Med 1978; 35:104-8.

${ }^{13}$ Enterline PE, Henderson V. The health of retired fibrous glass workers. Arch Environ Health 1975;30:113-6.

${ }^{14}$ Redmond CK, Breslin PP. Comparison of methods for assessing occupational hazards. J Occup Med 1975; 17:313-7.

${ }^{15}$ Koskela R-S, Hernberg S, Kärävä R, Järvinen E, Nurminen M. A mortality study of foundry workers. Scand J Work, Environ and Health 1976;2:suppl 1:73-89.

${ }^{16}$ Central Statistical Office of Finland. Statistical yearbook of Finland 1970. Helsinki: CSO, 1971.

\section{The February 1980 issue}

\section{THE FEBRUARY 1980 ISSUE CONTAINS THE FOLLOWING PAPERS}

Procedures for screening chemicals for carcinogenicity I F H PURCHASE

Dust exposure and mortality in chrysotile mining, 1910-75 J C MCDONALD, F D K LIDDELL, G W GIBBS, G E EYSSEN, AND A D MCDONALD

Concentrations and dimensions of coated and uncoated asbestos fibres in the human lung $A$ MORGAN AND A HOLMES

Nature, structure, and properties of asbestos cement dust J BAETEN, J HELSEN, AND A DERUYTTERE

Predictable "individual differences" in uptake and excretion of gases and lipid soluble vapours simulation study VERA FISEROVA-BERGEROVA, JIRI VLACH, AND JANET C CASSADY

Effects of urinary volume on urinary concentrations of lead, $\delta$-aminolaevulinic acid, coproporphyrin, creatinine, and total solutes S ARAKI

Microbial and immunological investigations and Information section

Copies are still available and may be obtained from the PUBLISHING MANAGER, BRITISH MEDICAL ASSOCIATION, TAVISTOCK SQUARE, LONDON WC1H 9JR, price $£ 4.25$ (USA \$9.20), including postage

remedial action after an outbreak of humidifier fever J H EDWARDS

Reproducibility of pulmonary function tests under laboratory and field conditions R G LOVE, M D ATTFIELD, AND K D ISLES

Interaction of calcium and lead in human erythrocytes C N ONG AND W R LEE

Distribution of lead-203 in human peripheral blood in vitro $\mathrm{C} N$ ONG AND $W$ R LEE

Mortality of workers on an isopropyl alcohol plant and two MEK dewaxing plants M R ALDERSON AND N S RATTAN

Notes and miscellanea

Unusual presentation of Osgood-Schlatter's disease E S HODGSON, Y S KAPLAN, AND $N$ R $V$ EDMONDS

Book reviews 